\title{
Mass Transfer Studies on Adsorption of Phenol from Wastewater Using Lantana camara, Forest Waste
}

\author{
C. R. Girish ${ }^{1}$ and V. Ramachandra Murty ${ }^{2}$ \\ ${ }^{1}$ Department of Chemical Engineering, Manipal Institute of Technology, Manipal 576104, India \\ ${ }^{2}$ Department of Biotechnology, Manipal Institute of Technology, Manipal 576104, India \\ Correspondence should be addressed to C. R. Girish; girishcrl@rediffmail.com
}

Received 25 July 2015; Accepted 28 January 2016

Academic Editor: Jose C. Merchuk

Copyright (c) 2016 C. R. Girish and V. R. Murty. This is an open access article distributed under the Creative Commons Attribution License, which permits unrestricted use, distribution, and reproduction in any medium, provided the original work is properly cited.

\begin{abstract}
Adsorption is one of the important treatment methods for the removal of pollutants from wastewater. The determination of rate controlling step in the process is important in the design of the process. Therefore, in the present work, mass transfer studies were done to evaluate the rate-limiting step in the adsorption of phenol from aqueous solution onto Lantana camara. Different mass transfer models were used to find the rate-limiting step and also to find the values of external mass transfer coefficient and diffusion coefficient. The Biot number was found to investigate the importance of external mass transfer to intraparticle diffusion. From the various models studied and the Biot numbers obtained, it was found that the adsorption on Lantana camara was controlled by film diffusion. The sensitivity analysis was performed to study the significance of the model parameters on the adsorption process.
\end{abstract}

\section{Introduction}

In the recent time, the increased industrial activities have escalated more environmental problems such as the contamination of water sources due to the accumulation of various toxic pollutants from the industrial wastewater. Phenol, one of the prominent pollutants in the wastewater, has been designated as priority pollutant by the environmental regulations [1]. Its permissible concentration should be less than $0.1 \mathrm{mg} / \mathrm{L}$ before it is released into the aquatic environment [1]. Phenol is introduced into the aquatic environment from the wastewater released from various industries such as pesticide, paper and pulp, resin, petrochemicals, fertilizers, and pharmaceutical industries and petroleum refineries [2]. It also causes harmful effects on the human health and aquatic life. Therefore, there is a need to treat phenol from wastewater before it is released into the environment.

Various treatment methods like biodegradation, biosorption, pervaporation, membrane separation process, extraction, adsorption on activated carbon, and advanced oxidation processes were used to treat phenol compounds from wastewater [3]. Adsorption using activated carbon is considered to be an effective wastewater treatment. But because of the expensive nature of activated carbon, there is a growing interest in producing an adsorbent from low cost agricultural materials. Therefore, Lantana camara, an invasive poisonous forest weed found in the tropical moist deciduous forests, that is, eastern side of Western Ghats in Coorg region, Karnataka, India, was selected for adsorbent preparation [4]. Due to the infestation, the forest weed eliminates the native species and results in decreased biodiversity. It is considered as poisonous, as the weed harbors pests such as malarial mosquitoes and tsetse flies, resulting in serious health issues. Therefore, by using this weed for the adsorbent preparation, it can reduce the problem of disposing of the forest waste. In the previous work, the batch experiments were carried out to investigate adsorption isotherm, adsorption kinetics, and adsorption thermodynamics [5]. But the literature on the mass transfer studies on the adsorption of phenol from adsorbent is limited. Mass transfer studies are also required for finding the rate-limiting step.

Mass transfer finds extensive applications in chemical engineering separation processes, where material balance on components is performed. For separation processes, 
thermodynamics determine the extent of separation, while mass transfer determines the rate at which the separation will occur [6].

Adsorption is a time-dependent process. In the removal of phenol from wastewater, it is required to know the rate of adsorption for design, operation control, and evaluation of adsorbent [7-9]. The transport of pollutant from the liquid phase to the solid phase is carried out by transfer of mass from one phase to another phase [10]. Therefore, to understand the suitability of the adsorbent for any adsorption process and efficiency of the process and for the design of wastewater treatment plants, it is required to know the steps involved in the adsorption of a pollutant from the aqueous solution [11].

It is studied that adsorption on an adsorbent from the aqueous phase involves three steps:

(i) Transport of the solute from bulk solution to the film surrounding the adsorbent (film diffusion).

(ii) Internal diffusion of solute from the film to the pores of the adsorbent.

(iii) Adsorption of the adsorbate on the external surface of the adsorbent through binding of the ions to the active sites [10, 12-15].

The slowest of these steps will control the process or will be the rate-limiting step. It will also determine the overall rate of the process. Therefore, the prediction of adsorption ratelimiting step is an important aspect for the study and design of adsorption process.

It is assumed that the third step is rapid when compared to the first two steps. This may be because of the following reasons. In a well agitated solid/liquid adsorber, mixing in the liquid is very rapid. Therefore, the concentration of adsorbate and concentration of the particles within the system are assumed to be uniform throughout $[12,16]$. The step is also considered as equilibrium step, because the equilibrium between solute in solution and solute on adsorbent is established instantaneously. Thus, the amount of solute adsorbed on the pore surface is at equilibrium with the solute concentration in the solution $[8,17]$.

Therefore, in the adsorption process, there are mainly two mass transfer resistance types, external and internal diffusion [18]. However, the controlling step may exist between intraparticle and external transport mechanisms. The rate determining step depends on various factors like the particle size of the adsorbent, degree of mixing, and affinity of solute for adsorbent. It is studied that external transport is usually the rate-limiting step for a system having poor mixing, dilute solute concentration, small particle size of adsorbent, and high affinity of solute for adsorbent, whereas intraparticle step controls the process for a system having good mixing, high solute concentration, larger particle size of adsorbent, and low affinity of solute for adsorbent $[19,20]$.

In the current work, mass transfer studies were done to determine the rate-limiting step for the adsorption of phenol from aqueous solution on Lantana camara. The possibility of this step was investigated from the kinetic data by using various mass transfer models available from the literature. The rate-limiting step was also determined
TABLE 1: The characterisation of the adsorbent treated with $\mathrm{HCl}$ and $\mathrm{KOH}$.

\begin{tabular}{|c|c|c|}
\hline Parameter & $\begin{array}{c}\text { Adsorbent } \\
\text { treated with } \mathrm{HCl}\end{array}$ & $\begin{array}{c}\text { Adsorbent treated } \\
\text { with } \mathrm{KOH}\end{array}$ \\
\hline Density, $\mathrm{g} / \mathrm{mL}$ & 0.2103 & 0.2248 \\
\hline Particle size, $\mu \mathrm{m}$ & 11.59 & 11.68 \\
\hline Particle porosity & 0.265 & 0.282 \\
\hline $\begin{array}{l}\text { Surface area per unit volume } \\
\text { of particle free slurry, } \mathrm{m}^{-1}\end{array}$ & 12559 & 12913.2 \\
\hline
\end{tabular}

through dimensionless number that is Biot number [21, 22] and sensitivity analysis.

\section{Materials and Methods}

2.1. Adsorbent. The material Lantana camara was initially washed with distilled water to remove all the earthy matter. The materials were then dried in sunlight for $48 \mathrm{~h}$, made into pieces, ground to fine powder, and sieved to particle sizes of less than $0.075 \mathrm{~mm}$. To produce the chemically treated carbon and to improve the properties of the raw powder, various chemicals such as $\mathrm{H}_{3} \mathrm{PO}_{4}, \mathrm{KNO}_{3}, \mathrm{H}_{2} \mathrm{SO}_{4}, \mathrm{ZnCl}_{2}, \mathrm{HCl}$, and $\mathrm{KOH}$ were treated with powder at $105^{\circ} \mathrm{C}$ as discussed in the previous work [5]. The characterisation of the carbon treated with the above chemicals was carried out. Various parameters such as particle size, surface area, pore volume, and percent removal of phenol were measured. From the preliminary results, the best two adsorbents treated with $\mathrm{HCl}$ and $\mathrm{KOH}$ were used for batch studies as described in the previous work [5]. The mass transfer studies were carried out with both adsorbents. The properties of both adsorbents required for mass transfer studies are shown in Table 1.

2.2. Adsorbate. Phenol has a chemical formula $\mathrm{C}_{6} \mathrm{H}_{5} \mathrm{OH}$ with a molecular weight of $94 \mathrm{~g} / \mathrm{mol}$. Phenol of analytical grade (Merck India Ltd.) was used for the preparation of stock solution of concentration $1000 \mathrm{mg} / \mathrm{L}$. The experimental solutions of concentrations 25, 50, 100, 150, 200, and $250 \mathrm{mg} / \mathrm{L}$ were prepared by diluting the stock solution to the required proportions. The other chemicals, potassium hydroxide (Merck India Ltd., AR grade), potassium nitrate (Merck India Ltd., AR grade), zinc chloride (Merck India Ltd., AR grade), hydrochloric acid (SD Fine Chemicals, India, AR grade), sulphuric acid (SD Fine Chemicals, India, AR grade), and orthophosphoric acid (SD Fine Chemicals, India, AR grade), were used for the chemical treatment of carbon.

2.3. Adsorption Experiments. The batch experiments were conducted with adsorbent treated with $\mathrm{HCl}$ and $\mathrm{KOH}$. The adsorbent was treated with $200 \mathrm{~mL}$ solution of $25,50,100,150$, 200 , and $250 \mathrm{mg} / \mathrm{L}$ concentrated phenol solution placed in $250 \mathrm{~mL}$ standard flask. $0.75 \mathrm{~g}$ and $1 \mathrm{~g}$ of the adsorbent treated with $\mathrm{HCl}$ and $\mathrm{KOH}$, respectively, were added to the flask and placed in a shaker at $298 \mathrm{~K}$, with rotation speed of $140 \mathrm{rpm}$. The flask containing adsorbent treated with $\mathrm{HCl}$ and $\mathrm{KOH}$ was agitated for $510 \mathrm{~min}$ and $570 \mathrm{~min}$, respectively, until the 
equilibrium was reached. The aqueous samples were collected at regular intervals of time. The concentration of phenol adsorbed was measured using UV-vis spectrophotometer.

2.4. Theoretical Investigation. For any adsorption process, it is important to know the extent of transfer of pollutant species from bulk to the surface of the solid adsorbent particles and at the interface of solid adsorbent particles or at the interface of liquid and solid particles. The slowest of these steps will be the controlling process. Therefore, in order to find the ratelimiting step, various mass transfer models were examined and also some dimensionless number and sensitivity analysis were studied.

2.4.1. External Diffusion Model. When the transport of the solute molecules from the liquid phase to the solid phase boundary plays an important role in adsorption, then the liquid film diffusion model can be applied. The external diffusion model assumes that the concentration at the adsorbent surface tends to zero or the intraparticle resistance is negligible $[8,23]$ and the intraparticle diffusion can be neglected at early times of contact $[8,23,24]$. This model is derived on the application of Fickien's laws, expressing the concentration of the solute in the solution, as a function of the difference in the concentrations of the solute in the solution and at the particle surface [25].

The change of solute concentration with respect to time can be written as follows:

$$
\frac{d C / C_{o}}{d t}=-k_{f} A
$$

where $C$ is the bulk liquid phase concentration of solute at any time $t, C_{o}$ is the initial concentration of phenol, $k_{f}$ is the external mass transfer coefficient, and $A$ is the surface area of adsorbent per unit volume of particle free slurry $\left(\mathrm{m}^{-1}\right)$ and is given by

$$
A=\frac{6 M}{V d_{p} \rho\left(1-\varepsilon_{p}\right)},
$$

where $V$ is the volume of solution (L), $M$ is the adsorbent mass $(\mathrm{g}), \varepsilon_{p}$ is bed porosity, and $\rho$ is bulk density $\left(\mathrm{g} / \mathrm{cm}^{3}\right)[12$, 16].

The external mass transfer coefficient $k_{f}$ can be calculated from the slope of the dimensionless curve, $C / C_{o}$, versus time $t$.

2.4.2. Furusawa and Smith Model. The effect of external mass transfer resistance on adsorption rate was analysed using the Furusawa and Smith model [26-30]. The mass transfer coefficient, $\beta_{L}\left(\mathrm{~m} \mathrm{~s}^{-1}\right)$, of phenol at the adsorbent-solution interface was determined by using

$$
\begin{aligned}
\ln \left(\frac{C_{t}}{C_{o}}-\frac{1}{1+m k_{L}}\right)= & \ln \left(\frac{m k_{L}}{1+m k_{L}}\right) \\
& -\left(\frac{1+m k_{L}}{m k_{L}}\right) \beta_{L} A t,
\end{aligned}
$$

where $k_{L}$ is a constant $(\mathrm{L} / \mathrm{g})$ and $m$ and $A$ are the mass and outer surface of the adsorbent particle per unit volume of particle free slurry $\left(\mathrm{g} / \mathrm{L}\right.$ and $\left.\mathrm{m}^{-1}\right)$, respectively. A linear plot of $\ln \left(C_{t} / C_{o}-1 /\left(1+m k_{L}\right)\right)$ versus $t$ was plotted and the coefficient $\beta_{L}$ was found. The value of $k_{L}$ was taken from the previous batch studies.

2.4.3. Furusawa and Smith Model (Modified) [31]. The proposed modified equation for external mass transfer is given by

$$
\left(\frac{1}{1+1 / m k_{L}}\right) \ln \left(\frac{C_{t}}{C_{o}}-\frac{1}{m k_{L}}\left(1-\frac{C_{t}}{C_{o}}\right)\right)=-k A t .
$$

The external mass transfer coefficient $k$ was calculated from the linear plot of the above equation. In (3), the intercept obtained $\ln \left(m k_{L} /\left(1+m k_{L}\right)\right)$ has to be adjusted to zero. But here the intercept will be zero.

2.4.4. Film Diffusion Model. Using Fick's equation, the diffusion process was studied on the exterior and interior surface of the adsorbent [32-34]. The equation at initial period of adsorption is given by

$$
\frac{q_{t}}{q_{e}}=6\left(\frac{D_{1}}{\pi a^{2}}\right)^{1 / 2} t^{1 / 2}
$$

The plot of $q_{t} / q_{e}$ versus $t^{1 / 2}$ represents mainly three stages of adsorption. The first linear portion related to the film diffusion, the second linear portion represented the intraparticle diffusion, and the last linear portion indicates adsorptiondesorption equilibrium [33]. From these regions, the ratelimiting step can be calculated.

2.4.5. Particle Diffusion Model. Due to the porous nature of the adsorbent, intraparticle mass diffusion can be the rate-limiting step $[33,35,36]$. The relationship between the adsorption capacities at any time and at equilibrium is given by

$$
\begin{aligned}
\ln \left[\frac{1}{1-F^{2}(t)}\right] & =\frac{\pi^{2}}{a^{2}} D_{e} t \\
F(t) & =\frac{q_{t}}{q_{e}},
\end{aligned}
$$

where $q_{t}$ and $q_{e}$ are amount of uptake at time $t$ and at equilibrium, respectively; $a$ is the particle radius. The diffusion coefficient $D_{e}$ is calculated by using the values obtained from the straight line plot of $-\ln \left(1-F^{2}(t)\right)$ versus $t$.

2.4.6. Mass Diffusivity. The values of diffusion coefficient mainly depend on the surface properties of adsorbents. The diffusion coefficients for the intraparticle transport of phenol within the pores of adsorbent particles have been investigated at different concentrations using the following expression:

$$
D_{m}=\frac{0.03 a^{2}}{t^{1 / 2}} \text {. }
$$


The mass diffusivity $\left(D_{m}\right)$ is inversely proportional to the half-reaction time $t^{1 / 2}$ [28]. Half-adsorption time, $t^{1 / 2}$, is defined as the time required for the adsorption to take up half as much what the adsorbent can take at its equilibrium value [37]. This time is also often used as a measure of the adsorption rate

$$
t^{1 / 2}=\frac{1}{k_{2} q_{e}},
$$

where $k_{2}$ and $q_{e}$ are the second-order rate constant and equilibrium adsorption capacity (taken from the previous batch studies [5]) and $a$ is the particle radius. It is assumed that the solid phase consists of spherical particles with an average radius between the radii corresponding to upper- and lower-size fractions $[28,38]$.

2.4.7. The Representation of Experimental Parameters $\left(k_{f}\right.$ and $D_{e}$ ) in terms of Dimensionless Group. The experimental parameters can also be represented in terms of dimensionless groups in order to study the mass transfer behaviour. The parameters were expressed in terms of Biot number to examine the rate-limiting step. An expression for Biot number (Bi) was derived in terms of concentration, to show the effect of concentration on the adsorption process. Biot number relates the external mass transfer resistance with the internal mass transfer resistance as follows [39]. It is the ratio of the rate of transport across the liquid layer to the rate of intraparticle mass transfer [40]. It can be used as a key factor for finding the rate-limiting step.

It is given by

$$
\mathrm{Bi}=\frac{k_{f} d}{D_{e}} .
$$

The adsorption process is mainly controlled by internal diffusion mechanism if $\mathrm{Bi}$ is greater than 100 and the adsorption process is controlled by film transfer if $\mathrm{Bi}$ is less than 100 [21].

2.4.8. Transport Number. The transport number is also used as criteria to know the mode of diffusion $[2,15]$. It is given by

$$
\frac{q_{t}}{q_{e}}=K_{m} t^{n},
$$

where $K_{m}$ is the adsorbent-adsorbate interaction coefficient and $n$ is the transport number. A straight plot of $\log \left(q_{t} / q_{e}\right)$ versus $\log t$ was made and the constants $K_{m}$ and $n$ were found. The values of $n$ show the type of transport mechanism. A value of $n=1$ indicates the non-Fickian mechanism and $n=$ 0.5 represents the Fickian mechanism (surface mechanism). The non-Fickian mechanism is applied when there is swelling or change in the structure [41]. The constant $K_{m}$ depends on the characteristics of the adsorbents.

2.4.9. Sensitivity Analysis. Sensitivity analysis was carried out to evaluate the significance of the mass transfer parameters on the adsorption process and also to find the rate controlling step. The parameter was changed about its base value while the other values were being kept constant [42]. The parameters selected were $k_{f}$ and $D_{e}$ and their effect on the concentration decay curve was investigated. The values of both $k_{f}$ and $D_{e}$ were varied from 0.5 to 2 times the base values while other parameters were kept constant and the sensitivity of the parameters was analysed. Finally, to study the effect of mass transfer coefficient in detail on the adsorption process, $k_{f}$ value was varied in the range $k_{f} / 4, k_{f} / 2, k_{f}, 2 k_{f}$, and $4 k_{f}$ and the nature of concentration decay curve obtained was analysed.

\section{Results and Discussion}

3.1. External Diffusion Model. It was observed that the mass transfer coefficient decreases with increase in phenol initial concentration and is shown in Table 2. The probable reason is that, by increasing the concentration, the driving force increases. Since the number of active sites on the adsorbent surface is fixed, by increasing the concentration, the mass transfer decreases. Therefore, with increasing concentration, the mass transfer coefficient decreases [18].

Another reason for this behaviour is that, from the adsorption equilibrium theory, the external mass transfer is dependent on the slope of the operating lines on equilibrium isotherms. Therefore, the higher the value of $C_{o}$, the lower the slope of the operating lines. Thus, mass transfer coefficient is related to the slope of the curves. Therefore, the mass transfer coefficient decreases with increase in concentration [16]. The external mass transfer is also the controlling factor when linearity of the model is obtained $[43,44]$. Similar results have been reported by other researchers in $[7,12,16,23]$.

3.2. Furusawa and Smith Model. The analysis of the data from Table 3 shows that the mass transfer coefficient obtained decreases with increased concentration of phenol. The results indicate that the values of regression coefficient ( $R^{2}$ values) obtained are well above 0.95 showing that external mass transfer can be the slowest step [27, 28]. The value of $\beta_{L}$ indicates the velocity of pollutant to move from liquid phase to the surface of the adsorbent to remove pollutant from wastewater. Therefore, the above model can be validated for the system.

3.3. Furusawa and Smith Model (Modified). Plotting the model is easier because the model intercept is equal to zero. From the values of the regression coefficient obtained as shown in Table 4, the model can be applied for the system. This signifies that surface mass transfer will dominate the process. These findings are the same as other research results [31].

3.4. Film Diffusion Model. The plot of $q_{t} / q_{e}$ versus $t^{1 / 2}$ was made and it represented three stages of adsorption. From Figures 1(a), 1(b), 1(c), 1(d), 1(e), 1(f), 2(a), 2(b), 2(c), 2(d), $2(\mathrm{e})$, and $2(\mathrm{f})$, the time taken for film diffusion, intraparticle diffusion, and adsorption process was found. Then, the ratio of time taken for film diffusion to the time taken for intraparticle diffusion was found and is shown in Tables 5 and 6 . If the above ratio is more than 1 , it shows that film diffusion is dominating the process. If the ratio is less than 1 , it indicates 
TABLE 2: Mass transfer coefficients from the external diffusion model for the adsorption of phenol.

\begin{tabular}{lcccc}
\hline \multirow{2}{*}{$C_{o}, \mathrm{mg} / \mathrm{L}$} & \multicolumn{2}{c}{ Adsorbent treated with $\mathrm{HCl}$} & \multicolumn{2}{c}{ Adsorbent treated with $\mathrm{KOH}$} \\
& $k_{f}, \mathrm{~m} / \mathrm{s}$ & $R^{2}$ & $1.55 \times 10^{-9}$ & $R^{2}$ \\
\hline 25 & $2.11 \times 10^{-9}$ & 0.9422 & $1.539 \times 10^{-9}$ & 0.9843 \\
50 & $2.070 \times 10^{-9}$ & 0.9572 & $1.5186 \times 10^{-9}$ & 0.9779 \\
100 & $2.0569 \times 10^{-9}$ & 0.9413 & $1.4977 \times 10^{-9}$ & 0.9785 \\
150 & $2.037 \times 10^{-9}$ & 0.9281 & $1.4924 \times 10^{-9}$ & 0.9729 \\
200 & $2.0304 \times 10^{-9}$ & 0.9276 & $1.4872 \times 10^{-9}$ & 0.9745 \\
250 & $2.0171 \times 10^{-9}$ & 0.9191 & 0.9774 \\
\hline
\end{tabular}

TABLE 3: Mass transfer coefficients from the Furusawa and Smith model for the adsorption of phenol.

\begin{tabular}{lcccc}
\hline \multirow{2}{*}{$C_{o}, \mathrm{mg} / \mathrm{L}$} & \multicolumn{2}{c}{ Adsorbent treated with $\mathrm{HCl}$} & \multicolumn{2}{c}{ Adsorbent treated with KOH } \\
& $\beta_{\mathrm{L}}, \mathrm{m} / \mathrm{s}$ & $R^{2}$ & $\beta_{L}, \mathrm{~m} / \mathrm{s}$ & $0.25 \times 10^{-9}$ \\
$R^{2}$ & $5.73 \times 10^{-9}$ & 0.9948 \\
25 & $8.5665 \times 10^{-9}$ & 0.9717 & $5.4166 \times 10^{-9}$ & 0.9925 \\
50 & $7.9075 \times 10^{-9}$ & 0.9828 & $5.0015 \times 10^{-9}$ & 0.9904 \\
100 & $7.512 \times 10^{-9}$ & 0.966 & $4.79315 \times 10^{-9}$ & 0.99 \\
150 & $7.1168 \times 10^{-9}$ & 0.9525 & $4.68 \times 10^{-9}$ & 0.9904 \\
200 & $6.4578 \times 10^{-9}$ & 0.9534 & 0.9545 & 0.9891 \\
\hline
\end{tabular}

TABle 4: Mass transfer coefficients from the Furusawa and Smith model (modified) for the adsorption of phenol.

\begin{tabular}{lcccc}
\hline \multirow{2}{*}{$C_{o}, \mathrm{mg} / \mathrm{L}$} & \multicolumn{2}{c}{ Adsorbent treated with $\mathrm{HCl}$} & \multicolumn{2}{c}{ Adsorbent treated with KOH } \\
& $k, \mathrm{~m} / \mathrm{s}$ & $R^{2}$ & $6.598 \times 10^{-9}$ & $R^{2}$ \\
\hline 25 & $9.2894 \times 10^{-9}$ & 0.9419 & $6.179 \times 10^{-9}$ & 0.9841 \\
50 & $8.62 \times 10^{-9}$ & 0.9568 & $5.55 \times 10^{-9}$ & 0.9776 \\
100 & $8.3605 \times 10^{-9}$ & 0.941 & $5.44 \times 10^{-9}$ & 0.9773 \\
150 & $7.9624 \times 10^{-9}$ & 0.9278 & $5.2367 \times 10^{-9}$ & 0.9726 \\
200 & $7.43 \times 10^{-9}$ & 0.9272 & $5.1320 \times 10^{-9}$ & 0.9743 \\
250 & $7.298 \times 10^{-9}$ & 0.9186 & 0.9751 \\
\hline
\end{tabular}

TABLE 5: The time taken by the adsorbent treated with $\mathrm{HCl}$ for the three different stages of adsorption.

\begin{tabular}{|c|c|c|c|c|}
\hline $\begin{array}{l}\mathrm{HCl} \text { treated adsorbent, } \\
\text { concentration }\end{array}$ & $\begin{array}{l}\text { Time taken for film } \\
\text { diffusion, min }\end{array}$ & $\begin{array}{c}\text { Time taken for } \\
\text { intraparticle diffusion, } \\
\text { min }\end{array}$ & $\begin{array}{l}\text { Time taken for } \\
\text { adsorption, min }\end{array}$ & $\begin{array}{l}\text { Ratio of time taken for } \\
\text { film diffusion to that for } \\
\text { intraparticle diffusion }\end{array}$ \\
\hline $25 \mathrm{mg} / \mathrm{L}$ & 174.4 & 39.7 & 9 & 4.39 \\
\hline $50 \mathrm{mg} / \mathrm{L}$ & 110.25 & 64 & 49 & 1.722 \\
\hline $100 \mathrm{mg} / \mathrm{L}$ & 196 & 36 & 4 & 5.44 \\
\hline $150 \mathrm{mg} / \mathrm{L}$ & 182.25 & 42.25 & 6.25 & 4.31 \\
\hline $200 \mathrm{mg} / \mathrm{L}$ & 144 & 30.25 & 25 & 4.76 \\
\hline $250 \mathrm{mg} / \mathrm{L}$ & 156.25 & 56.25 & 6.25 & 2.77 \\
\hline
\end{tabular}

TABLE 6: The time taken by the adsorbent treated with $\mathrm{KOH}$ for the three different stages of adsorption.

\begin{tabular}{|c|c|c|c|c|}
\hline $\mathrm{KOH}$ treated adsorbent & $\begin{array}{l}\text { Time taken for film } \\
\text { diffusion, min }\end{array}$ & $\begin{array}{c}\text { Time taken for } \\
\text { intraparticle diffusion, } \\
\text { min }\end{array}$ & $\begin{array}{l}\text { Time taken for } \\
\text { adsorption, min }\end{array}$ & $\begin{array}{l}\text { Ratio of time taken for } \\
\text { film diffusion to that for } \\
\text { intraparticle diffusion }\end{array}$ \\
\hline $25 \mathrm{mg} / \mathrm{L}$ & 104.04 & 92.16 & 16 & 1.128 \\
\hline $50 \mathrm{mg} / \mathrm{L}$ & 156.25 & 56.25 & 14.44 & 2.77 \\
\hline $100 \mathrm{mg} / \mathrm{L}$ & 163.84 & 59.84 & 10.89 & 2.73 \\
\hline $150 \mathrm{mg} / \mathrm{L}$ & 169 & 42.25 & 23.04 & 4 \\
\hline $200 \mathrm{mg} / \mathrm{L}$ & 144 & 44.89 & 26.01 & 3.2078 \\
\hline $250 \mathrm{mg} / \mathrm{L}$ & 146.41 & 60.84 & 15.21 & 2.4064 \\
\hline
\end{tabular}




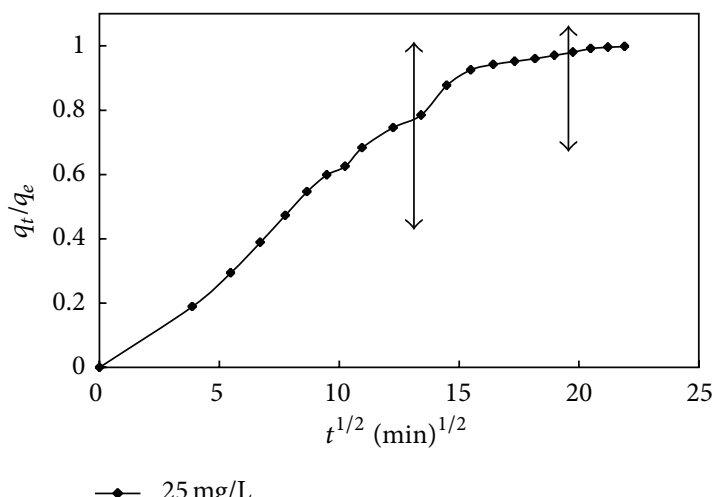

(a)

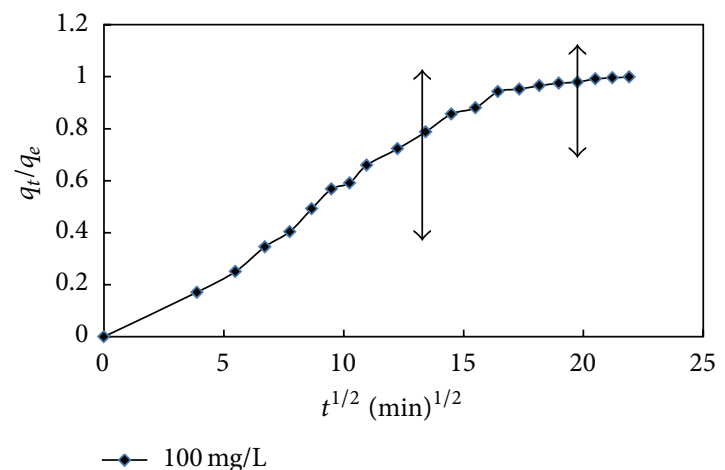

(c)

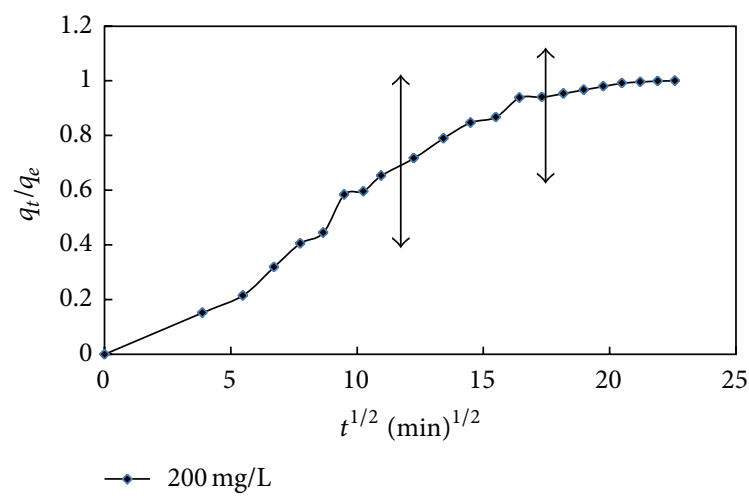

(e)

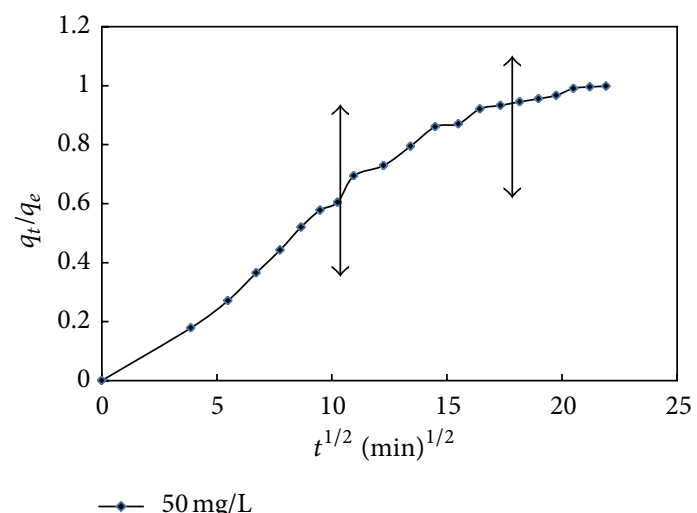

(b)

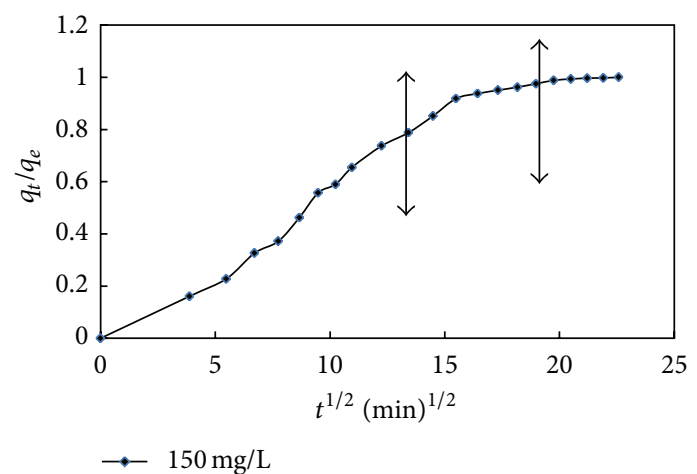

(d)

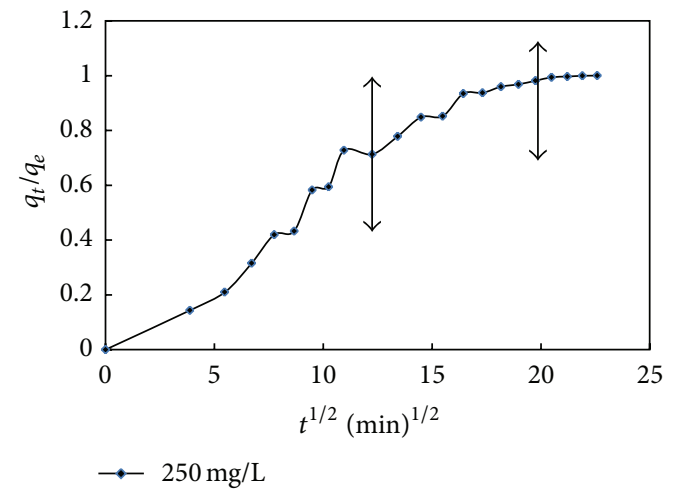

(f)

FIGURE 1: The plot of $q_{t} / q_{e}$ versus $t^{1 / 2}$ showing all three regions for adsorbent treated with $\mathrm{HCl}$ for the adsorption of phenol.

that the process is controlled by intraparticle diffusion. From the results, it was found that the ratio is more than 1 , showing that film diffusion is the slowest step [33].

3.5. Particle Diffusion Model. From the values of the correlation coefficient obtained as shown in Table 7, it was found that the model could not be validated for the system $[35,45,46]$. The calculated $R^{2}$ values show agreement of experimental points with the model proposed. The values of the calculated diffusion coefficients do not change with phenol concentration, which shows that they are independent of the initial concentration of solution [46]. From the values of $D_{e}$ obtained $\left(10^{-9}\right.$ to $\left.10^{-17} \mathrm{~m}^{2} / \mathrm{s}\right)$, it can be suggested that it is applied for chemisorption system [33, 45]. A similar trend has been reported in [27].

3.6. Mass Diffusivity. The diffusion coefficients are calculated by taking various factors like concentration, dosage, $\mathrm{pH}$, and temperature into consideration. The values obtained were in the range of $1.282 \times 10^{-16}$ to $2.85 \times 10^{-16} \mathrm{~m}^{2} / \mathrm{s}$ and $1.3989 \times 10^{-16}$ to $2.004 \times 10^{-16} \mathrm{~m}^{2} / \mathrm{s}$ for adsorbent treated with $\mathrm{HCl}$ and $\mathrm{KOH}$, respectively, and are shown in Table 8. 


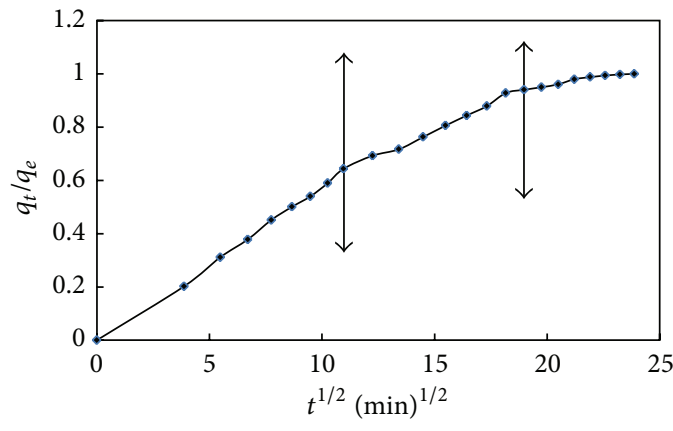

$\rightarrow-25 \mathrm{mg} / \mathrm{L}$

(a)

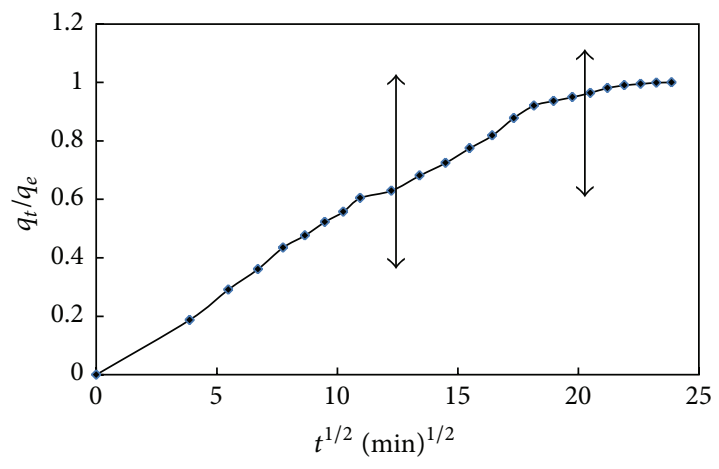

$100 \mathrm{mg} / \mathrm{L}$

(c)

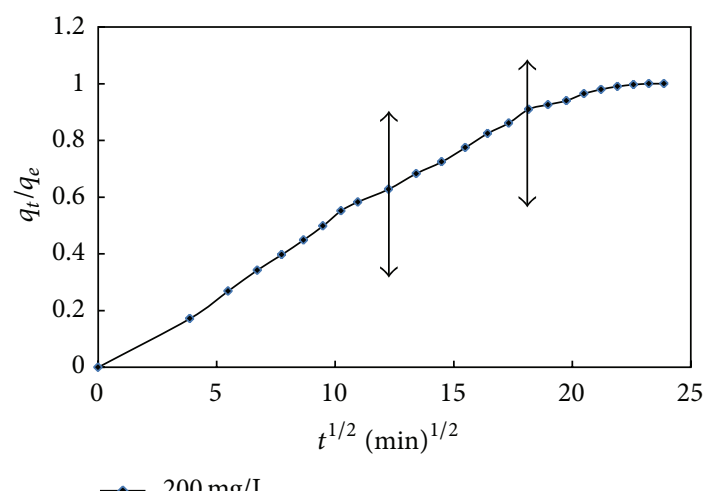

(e)

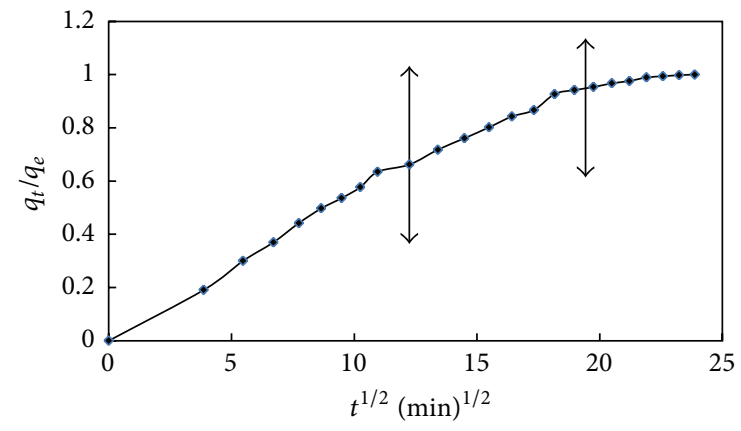

$50 \mathrm{mg} / \mathrm{L}$

(b)

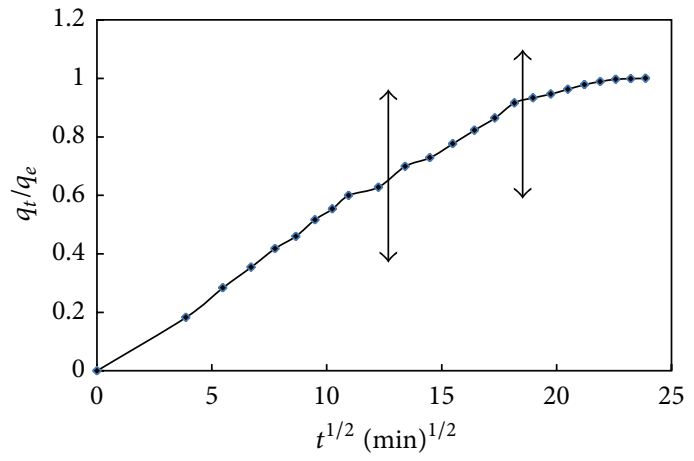

$150 \mathrm{mg} / \mathrm{L}$

(d)

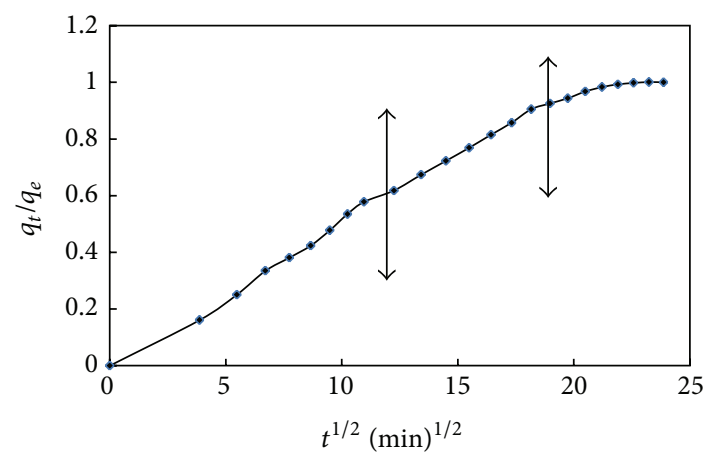

$\rightarrow-250 \mathrm{mg} / \mathrm{L}$

(f)

FIGURE 2: The plot of $q_{t} / q_{e}$ versus $t^{1 / 2}$ showing all three regions for adsorbent treated with $\mathrm{KOH}$ for the adsorption of phenol.

TABLE 7: The values of diffusion coefficients from the particle diffusion model at different concentrations.

\begin{tabular}{lcccc}
\hline \multirow{2}{*}{$C_{o}, \mathrm{mg} / \mathrm{L}$} & \multicolumn{2}{c}{ Adsorbent treated with $\mathrm{HCl}$} & \multicolumn{2}{c}{ Adsorbent treated with KOH } \\
& $D_{e}, \mathrm{~m}^{2} / \mathrm{s}$ & $R^{2}$ & $D_{e}, \mathrm{~m}^{2} / \mathrm{s}$ & $R^{2}$ \\
\hline 25 & $5.0471 \times 10^{-16}$ & 0.9211 & $3.7433 \times 10^{-16}$ & 0.904 \\
50 & $4.99 \times 10^{-16}$ & 0.877 & $3.7555 \times 10^{-16}$ & 0.8997 \\
100 & $5.0187 \times 10^{-16}$ & 0.8868 & $3.7435 \times 10^{-16}$ & 0.8718 \\
150 & $4.9904 \times 10^{-16}$ & 0.9114 & $3.7435 \times 10^{-16}$ & 0.8438 \\
200 & $4.9904 \times 10^{-16}$ & 0.8669 & $3.7550 \times 10^{-16}$ & 0.8352 \\
250 & $5.0471 \times 10^{-16}$ & 0.8339 & $3.9163 \times 10^{-16}$ & 0.8063 \\
\hline
\end{tabular}


TABLE 8: The values of diffusion coefficient for both adsorbents at different concentrations.

\begin{tabular}{lcccc}
\hline \multirow{2}{*}{$C_{o}, \mathrm{mg} / \mathrm{L}$} & \multicolumn{2}{c}{ Adsorbent treated with $\mathrm{HCl}$} & \multicolumn{2}{c}{ Adsorbent treated with $\mathrm{KOH}$} \\
& $t^{1 / 2}, \mathrm{~s}$ & $D_{m}, \mathrm{~m}^{2} / \mathrm{s}$ & $D_{m}, \mathrm{~m}^{2} / \mathrm{s}$ \\
\hline 25 & 3533.19 & $2.85 \times 10^{-16}$ & 5105.47 & $2.004 \times 10^{-16}$ \\
50 & 5309.88 & $1.8375 \times 10^{-16}$ & 5531.36 & $1.8494 \times 10^{-16}$ \\
100 & 6844.20 & $1.4719 \times 10^{-16}$ & 5489.67 & $1.86 \times 10^{-16}$ \\
150 & 7853.91 & $1.282 \times 10^{-16}$ & 5690.28 & $1.7977 \times 10^{-16}$ \\
200 & 7086.54 & $1.4216 \times 10^{-16}$ & 6421.25 & $1.593 \times 10^{-16}$ \\
250 & 6304.90 & $1.5979 \times 10^{-16}$ & 7312.40 & $1.3989 \times 10^{-16}$ \\
\hline
\end{tabular}

TABLE 9: The values of Biot number for both adsorbents at different initial concentrations.

\begin{tabular}{lccccc}
\hline \multirow{2}{*}{$C_{o}, \mathrm{mg} / \mathrm{L}$} & \multicolumn{2}{c}{ Adsorbent treated with $\mathrm{HCl}$} & \multirow{2}{*}{$\mathrm{Bi}$} & \multicolumn{2}{c}{ Adsorbent treated with KOH } \\
& $k_{f}, \mathrm{~m} / \mathrm{s}$ & $D_{e}, \mathrm{~m}^{2} / \mathrm{s}$ & & $k_{f}, \mathrm{~m} / \mathrm{s}$ & $D_{e}, \mathrm{~m}^{2} / \mathrm{s}$ \\
\hline 25 & $2.11 \times 10^{-9}$ & $5.0471 \times 10^{-16}$ & 48.3275 & $1.55 \times 10^{-9}$ & $3.7433 \times 10^{-16}$ \\
50 & $2.070 \times 10^{-9}$ & $4.99 \times 10^{-16}$ & 47.9501 & $1.539 \times 10^{-9}$ & $3.7555 \times 10^{-16}$ \\
100 & $2.0569 \times 10^{-9}$ & $5.0187 \times 10^{-16}$ & 47.3774 & $1.5186 \times 10^{-9}$ & $3.7435 \times 10^{-16}$ \\
150 & $2.037 \times 10^{-9}$ & $4.9904 \times 10^{-16}$ & 47.1857 & $1.4977 \times 10^{-9}$ & $3.7435 \times 10^{-16}$ \\
200 & $2.0304 \times 10^{-9}$ & $4.9904 \times 10^{-16}$ & 47.0328 & $1.4924 \times 10^{-9}$ & $3.7550 \times 10^{-16}$ \\
250 & $2.0171 \times 10^{-9}$ & $5.0471 \times 10^{-16}$ & 46.1997 & $1.4872 \times 10^{-9}$ & $3.9163 \times 10^{-16}$ \\
\hline
\end{tabular}

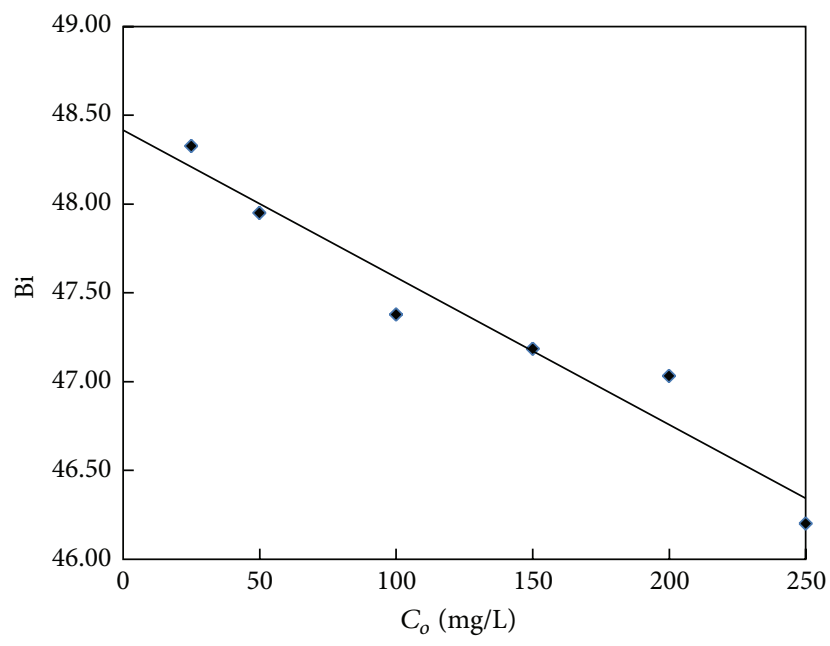

FIGURE 3: The effect of initial concentration on the Biot number for adsorbent treated with $\mathrm{HCl}$.

$D_{m}$ values obtained in our study were compared with the values available from the literature. Similar results have been reported by other researchers [11, 47].

\subsection{The Representation of Experimental Parameters in terms} of Biot Number. The calculated external mass transfer coefficients and diffusion coefficients were expressed in the form of Biot number and are shown in Table 9. The dimensionless numbers obtained are less than 100 . This indicates that the adsorption of phenol onto the adsorbent is controlled by external film mass transfer. Similar observations have been made by authors [21].

The effect of phenol initial concentration on dimensionless mass transfer number is shown in Figures 3 and

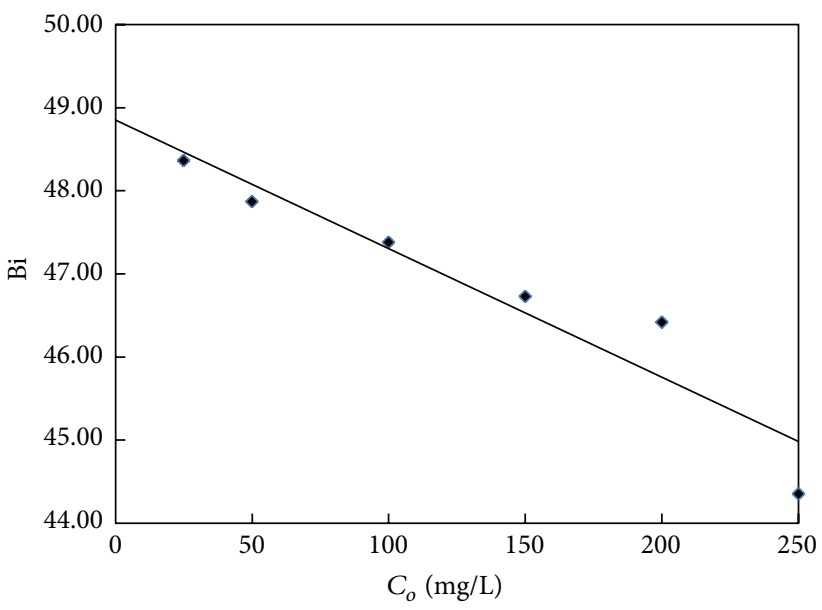

FIgURE 4: The effect of initial concentration on the Biot number for adsorbent treated with $\mathrm{KOH}$.

4. From the linearity of the curve as shown in Figures 3 and 4, (11) and (12) were obtained for adsorbent treated with $\mathrm{HCl}$ and adsorbent treated with $\mathrm{KOH}$, respectively. The expression shows the relation between initial concentration and the Biot number. It was also found that the mass transfer decreases with increasing phenol concentration. The results were similar to those discussed in the film diffusion model. The regression coefficients were found to be 0.9433 and 0.9068 for adsorbent treated with $\mathrm{HCl}$ and adsorbent treated with $\mathrm{KOH}$, respectively. Similar expressions were obtained by the authors $[12,48]$ :

$$
\begin{aligned}
& \mathrm{Bi}=48.416\left(C_{o}\right)^{-0.0083}, \\
& \mathrm{Bi}=48.851\left(C_{o}\right)^{-0.0155} .
\end{aligned}
$$


TABLE 10: The transport number and the model constant for both adsorbents at different initial concentrations.

\begin{tabular}{llccc}
\hline \multirow{2}{*}{$C_{o}, \mathrm{mg} / \mathrm{L}$} & \multicolumn{2}{c}{ Adsorbent treated with HCl } & \multicolumn{2}{c}{ Adsorbent treated with KOH } \\
& $n$ & $k_{m}$ & 0.4208 & 0.0774 \\
25 & 0.4514 & 0.0704 & 0.4338 & 0.07164 \\
50 & 0.4717 & 0.0618 & 0.4442 & 0.0665 \\
100 & 0.5003 & 0.05262 & 0.4538 & 0.06284 \\
150 & 0.5274 & 0.04516 & 0.4718 & 0.05641 \\
200 & 0.5339 & 0.04334 & 0.4924 & 0.04985 \\
250 & 0.5417 & 0.04162 & & \\
\hline
\end{tabular}

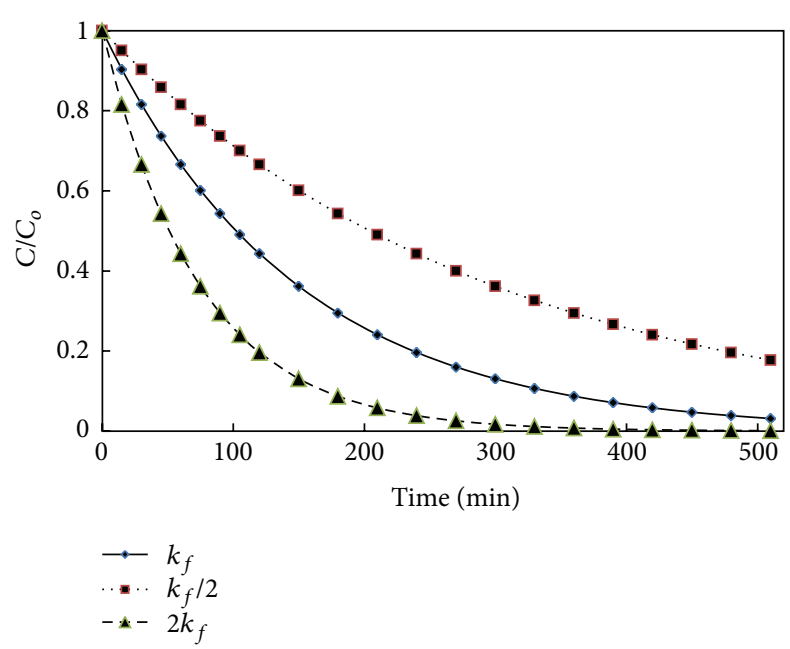

FIGURE 5: The plot of sensitivity analysis for showing the effect of $k_{f}$ on the adsorption process for the adsorbent treated with $\mathrm{HCl}$.

3.8. Transport Number. The values of $k_{m}$ and $n$ were calculated and are shown in Table 10. It was found that the transport number, $n$, was found to be less than 0.5 , thus showing that the adsorption follows Fickian diffusion mechanism, where phenols interact on the surface of the adsorbents. These results are similar to those reported by authors $[2,15]$.

3.9. Sensitivity Analysis. The values of both $k_{f}$ and $D_{e}$ for the adsorbent treated with $\mathrm{HCl}$ were varied from 0.5 to 2 times the base values while other experimental conditions were kept constant. It was observed that the concentration curve was very sensitive to the external mass transfer coefficient. The spreading of the concentration curves was more as shown in Figure 5. All the curves covered larger concentration region.

But varying the value of $D_{e}$ within the selected range has a little effect on the concentration curve. As it can be seen from Figure 6, for various values of $D_{e}$ concentration curve was covered to lesser extent. This shows that the external mass transfer has more influence on the mass transfer of phenol from the aqueous solution. This also signifies that the external mass transfer resistance is more important than the internal mass transfer resistance. A similar trend has been reported in $[49,50]$.

To study the effect of mass transfer coefficient of the adsorption process in detail, $k_{f}$ value for the adsorbent

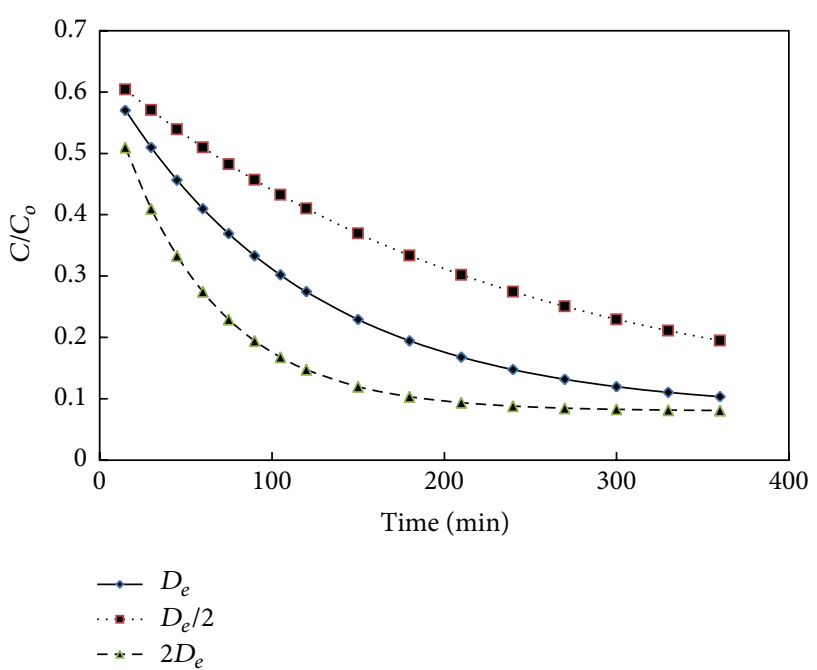

FIGURE 6: The plot of sensitivity analysis for showing the effect of $D_{e}$ on the adsorption process for the adsorbent treated with $\mathrm{HCl}$.

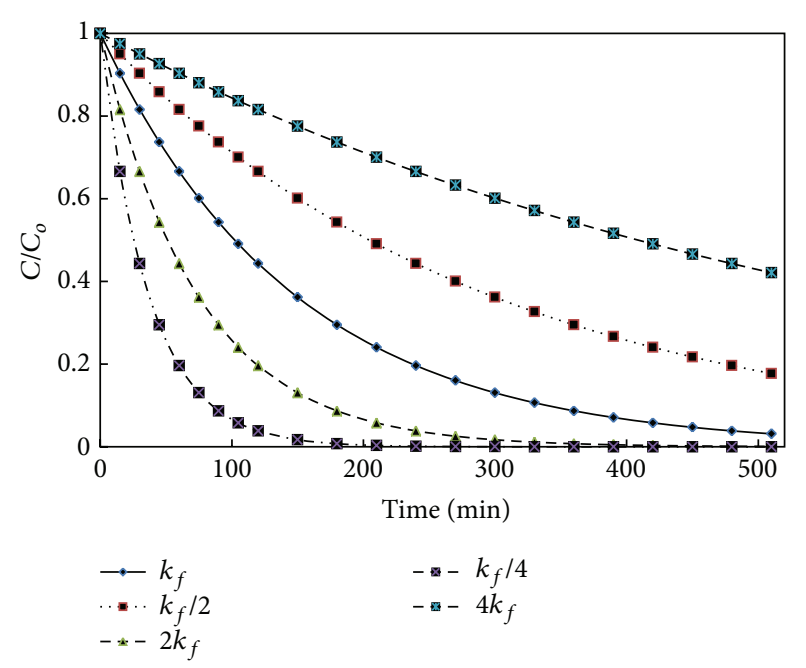

FIGURE 7: The effect of mass transfer coefficient on the adsorption process for the adsorbent treated with $\mathrm{HCl}$.

treated with $\mathrm{HCl}$ was varied in the range $k_{f} / 4, k_{f} / 2, k_{f}, 2 k_{f}$, and $4 k_{f}$ and was shown in Figure 7. It was found that when $k_{f}$ value increases, more mass transfer takes place and it takes less time for the total adsorption process. This is because of 
the reason that the larger the value of $k_{f}$, the smaller the film resistance, thereby leading to more mass transfer. This can be observed in the concentration decay curves. Similar results have been reported by other researchers $[51,52]$.

\section{Conclusion}

The current study shows that Lantana camara can be used as a potential adsorbent for the removal of phenol from aqueous solution. The mass transfer studies were carried out from the data obtained from the batch kinetic experiments. The ratelimiting step was found using various mass transfer models. The values of external mass transfer coefficient were obtained in the range of $1.4872 \times 10^{-9}$ to $9.2894 \times 10^{-9} \mathrm{~m} / \mathrm{s}$ and the intraparticle diffusion coefficient ranged from $1.3989 \times 10^{-16}$ to $5.0471 \times 10^{-16} \mathrm{~m}^{2} / \mathrm{s}$. The analysis of different mass transfer models shows the external mass transfer as the slowest step in the sorption process. The Biot number obtained in the range of less than 100 indicates that the process was controlled by film diffusion. An expression was derived which shows the correlation between the Biot number and the initial concentration of phenol. From the sensitivity analysis, it was found that the adsorption process is more dependent on $k_{f}$ than $D_{e}$.

\section{Conflict of Interests}

The authors declare that there is no conflict of interests regarding the publication of this paper.

\section{References}

[1] M. Ahmaruzzaman and D. K. Sharma, "Adsorption of phenols from wastewater," Journal of Colloid and Interface Science, vol. 287, no. 1, pp. 14-24, 2005.

[2] H. Polat, M. Molva, and M. Polat, "Capacity and mechanism of phenol adsorption on lignite," International Journal of Mineral Processing, vol. 79, no. 4, pp. 264-273, 2006.

[3] C. R. Girish and V. R. Murty, "Review of various treatment methods for the abatement of phenolic compounds from wastewater," Journal of Environmental Science \& Engineering, vol. 54, no. 2, pp. 306-316, 2012.

[4] N. Priyanka and P. K. Joshi, "A review of Lantana camara studies in India," International Journal of Scientific and Research Publications, vol. 3, no. 10, pp. 1-11, 2013.

[5] C. R. Girish and V. Ramachandra Murty, "Adsorption of phenol from aqueous solution using Lantana camara, forest Waste: kinetics, isotherm, and thermodynamic studies," International Scholarly Research Notices, vol. 2014, Article ID 201626, 16 pages, 2014.

[6] M. A. Fulazzaky, "Water quality evaluation system to assess the Brantas river water," Water Resources Management, vol. 23, no. 14, pp. 3019-3033, 2009.

[7] Ö. Tunç, H. Tanac1, and Z. Aksu, "Potential use of cotton plant wastes for the removal of Remazol Black B reactive dye," Journal of Hazardous Materials, vol. 163, no. 1, pp. 187-198, 2009.

[8] A. Y. Dursun and O. Tepe, "Removal of Chemazol Reactive Red 195 from aqueous solution by dehydrated beet pulp carbon," Journal of Hazardous Materials, vol. 194, pp. 303-311, 2011.

[9] T. S. Y. Choong, T. N. Wong, T. G. Chuah, and A. Idris, "Filmpore-concentration-dependent surface diffusion model for the adsorption of dye onto palm kernel shell activated carbon," Journal of Colloid and Interface Science, vol. 301, no. 2, pp. 436440, 2006.

[10] D. Mohan and K. P. Singh, "Single- and multi-component adsorption of cadmium and zinc using activated carbon derived from bagasse-an agricultural waste," Water Research, vol. 36, no. 9, pp. 2304-2318, 2002.

[11] Y. C. Sharma, Uma, S. N. Upadhyay, and C. H. Weng, "Studies on an economically viable remediation of chromium rich waters and wastewaters by PTPS fly ash," Colloids and Surfaces A: Physicochemical and Engineering Aspects, vol. 317, no. 1-3, pp. 222-228, 2008.

[12] K. V. Kumar and K. Porkodi, "Mass transfer, kinetics and equilibrium studies for the biosorption of methylene blue using Paspalum notatum," Journal of Hazardous Materials, vol. 146, no. 1-2, pp. 214-226, 2007.

[13] M. Doğan and M. Alkan, "Adsorption kinetics of methyl violet onto perlite," Chemosphere, vol. 50, no. 4, pp. 517-528, 2003.

[14] P. G. González and Y. B. Pliego-Cuervo, "Adsorption of Cd(II), $\mathrm{Hg}(\mathrm{II})$ and $\mathrm{Zn}$ (II) from aqueous solution using mesoporous activated carbon produced from Bambusa vulgaris striata," Chemical Engineering Research and Design, vol. 92, no. 11, pp. 2715-2724, 2014.

[15] R. Arasteh, M. Masoumi, A. M. Rashidi, L. Moradi, V. Samimi, and S. T. Mostafavi, "Adsorption of 2-nitrophenol by multiwall carbon nanotubes from aqueous solutions," Applied Surface Science, vol. 256, no. 14, pp. 4447-4455, 2010.

[16] G. M. Walker, L. Hansen, J.-A. Hanna, and S. J. Allen, "Kinetics of a reactive dye adsorption onto dolomitic sorbents," Water Research, vol. 37, no. 9, pp. 2081-2089, 2003.

[17] J. D. Méndez-Díaz, G. Prados-Joya, J. Rivera-Utrilla et al., "Kinetic study of the adsorption of nitroimidazole antibiotics on activated carbons in aqueous phase," Journal of Colloid and Interface Science, vol. 345, no. 2, pp. 481-490, 2010.

[18] K. A. Karimaian, A. Amrane, H. Kazemian, R. Panahi, and M. Zarrabi, "Retention of phosphorous ions on natural and engineered waste pumice: characterization, equilibrium, competing ions, regeneration, kinetic, equilibrium and thermodynamic study," Applied Surface Science, vol. 284, pp. 419-431, 2013.

[19] V. P. Mulgundmath, R. A. Jones, F. H. Tezel, and J. Thibault, "Fixed bed adsorption for the removal of carbon dioxide from nitrogen: breakthrough behaviour and modelling for heat and mass transfer," Separation and Purification Technology, vol. 85, pp. 17-27, 2012.

[20] A. Kumar, S. Kumar, and S. Kumar, "Adsorption of resorcinol and catechol on granular activated carbon: equilibrium and kinetics," Carbon, vol. 41, no. 15, pp. 3015-3025, 2003.

[21] R. K. Prasad and S. N. Srivastava, "Sorption of distillery spent wash onto fly ash: kinetics and mass transfer studies," Chemical Engineering Journal, vol. 146, no. 1, pp. 90-97, 2009.

[22] G. McKay and M. J. Bino, "Adsorption of pollutants from wastewater onto activated carbon based on external mass transfer and pore diffusion," Water Research, vol. 22, no. 3, pp. 279-286, 1988.

[23] Z. Aksu and I. A. Isoglu, "Use of agricultural waste sugar beet pulp for the removal of Gemazol turquoise blue-G reactive dye from aqueous solution," Journal of Hazardous Materials, vol. 137, no. 1, pp. 418-430, 2006.

[24] M. T. Sulak, E. Demirbas, and M. Kobya, "Removal of Astrazon Yellow 7GL from aqueous solutions by adsorption onto wheat bran," Bioresource Technology, vol. 98, no. 13, pp. 2590-2598, 2007. 
[25] M. Jansson-Charrier, E. Guibal, J. Roussy, B. Delanghe, and P. Le Cloirec, "Vanadium (IV) sorption by chitosan: kinetics and equilibrium," Water Research, vol. 30, no. 2, pp. 465-475, 1996.

[26] M. Kapur and M. K. Mondal, "Mass transfer and related phenomena for $\mathrm{Cr}(\mathrm{VI})$ adsorption from aqueous solutions onto Mangifera indica sawdust," Chemical Engineering Journal, vol. 218, pp. 138-146, 2013.

[27] D. Fu, Y. Zhang, F. Lv, P. K. Chu, and J. Shang, "Removal of organic materials from TNT red water by Bamboo Charcoal adsorption," Chemical Engineering Journal, vol. 193-194, pp. 3949, 2012.

[28] L. Khezami and R. Capart, "Removal of chromium(VI) from aqueous solution by activated carbons: kinetic and equilibrium studies," Journal of Hazardous Materials, vol. 123, no. 1-3, pp. 223-231, 2005.

[29] D. Batabyal, A. Sahu, and S. K. Chaudhuri, "Kinetics and mechanism of removal of 2, 4-dimethyl phenol from aqueous solutions with coal fly ash," Separations Technology, vol. 5, no. 4, pp. 179-186, 1995.

[30] P. Pendleton and S. H. Wu, "Kinetics of dodecanoic acid adsorption from caustic solution by activated carbon," Journal of Colloid and Interface Science, vol. 266, no. 2, pp. 245-250, 2003.

[31] K. K. H. Choy, D. C. K. Ko, C. W. Cheung, J. F. Porter, and G. McKay, "Film and intraparticle mass transfer during the adsorption of metal ions onto bone char," Journal of Colloid and Interface Science, vol. 271, no. 2, pp. 284-295, 2004.

[32] K. Inoue and K. Kawamoto, "Adsorption characteristics of carbonaceous adsorbents for organic pollutants in a model incineration exhaust gas," Chemosphere, vol. 70, no. 3, pp. 349-357, 2008.

[33] B. Singha and S. K. Das, "Biosorption of $\mathrm{Cr}(\mathrm{VI})$ ions from aqueous solutions: kinetics, equilibrium, thermodynamics and desorption studies," Colloids and Surfaces B: Biointerfaces, vol. 84, no. 1, pp. 221-232, 2011.

[34] Ç. Sarici-Özdemir and Y. Önal, "Equilibrium, kinetic and thermodynamic adsorptions of the environmental pollutant tannic acid onto activated carbon," Desalination, vol. 251, no. 13, pp. 146-152, 2010.

[35] D. L. Guerra and C. Airoldi, "Kinetics and modified clay thermodynamic from the Brazilian amazon region for lead removal," Journal of Hazardous Materials, vol. 159, no. 2-3, pp. 412-419, 2008.

[36] T. K. Naiya, A. K. Bhattacharya, and S. K. Das, "Removal of $\mathrm{Cd}(\mathrm{II})$ from aqueous solutions using clarified sludge," Journal of Colloid and Interface Science, vol. 325, no. 1, pp. 48-56, 2008.

[37] D. B. Singh, G. Prasad, and D. C. Rupainwar, "Adsorption technique for the treatment of As(V)-rich effluents," Colloids and Surfaces A: Physicochemical and Engineering Aspects, vol. 111, no. 1-2, pp. 49-56, 1996.

[38] M. Doğan, Y. Özdemir, and M. Alkan, "Adsorption kinetics and mechanism of cationic methyl violet and methylene blue dyes onto sepiolite," Dyes and Pigments, vol. 75, no. 3, pp. 701-713, 2007.

[39] N. E. Dávila-Guzman, F. J. Cerino-Córdova, P. E. Diaz-Flores, J. R. Rangel-Mendez, M. N. Sánchez-González, and E. SotoRegalado, "Equilibrium and kinetic studies of ferulic acid adsorption by Amberlite XAD-16," Chemical Engineering Journal, vol. 183, pp. 112-116, 2012.

[40] U. K. Traegner and M. T. Suidan, "Parameter evaluation for carbon adsorption," Journal of Environmental Engineering, vol. 115, no. 1, pp. 109-128, 1989.
[41] D. Kim, J. M. Caruthers, and N. A. Peppas, "Penetrant transport in crosslinked polystyrene," Macromolecules, vol. 26, no. 8, pp. 1841-1847, 1993.

[42] M. Rashidi, M. Nikazar, M. Rahmani, and Z. Mohamadghasemi, "Kinetic modeling of simultaneous dehydrogenation of propane and isobutane on Pt-Sn- $\mathrm{K} / \mathrm{Al}_{2} \mathrm{O}_{3}$ catalyst," Chemical Engineering Research and Design, vol. 95, pp. 239-247, 2015.

[43] S. Dutta, J. K. Basu, and R. N. Ghar, "Studies on adsorption of pnitrophenol on charred saw-dust," Separation and Purification Technology, vol. 21, no. 3, pp. 227-235, 2001.

[44] A. Quek and R. Balasubramanian, "Removal of copper by oxygenated pyrolytic tire char: kinetics and mechanistic insights," Journal of Colloid and Interface Science, vol. 356, no. 1, pp. $203-$ 210, 2011.

[45] C. P. Nanseu-Njiki, G. K. Dedzo, and E. Ngameni, "Study of the removal of paraquat from aqueous solution by biosorption onto Ayous (Triplochiton schleroxylon) sawdust," Journal of Hazardous Materials, vol. 179, no. 1-3, pp. 63-71, 2010.

[46] M. Trgo, J. Perić, and N. V. Medvidović, "A comparative study of ion exchange kinetics in zinc/lead-modified zeolite-clinoptilolite systems," Journal of Hazardous Materials, vol. 136, no. 3, pp. 938-945, 2006.

[47] G. McKay and V. J. P. Poots, "Kinetics and diffusion processes in colour removal from effluent using wood as an adsorbent," Journal of Chemical Technology and Biotechnology, vol. 30, no. 1, pp. 279-292, 1980.

[48] K. Porkodi and K. V. Kumar, "Equilibrium, kinetics and mechanism modeling and simulation of basic and acid dyes sorption onto jute fiber carbon: Eosin yellow, malachite green and crystal violet single component systems," Journal of Hazardous Materials, vol. 143, no. 1-2, pp. 311-327, 2007.

[49] X. Zhang, S. Chen, and H. T. Bi, "Application of wave propagation theory to adsorption breakthrough studies of toluene on activated carbon fiber beds," Carbon, vol. 48 , no. 8, pp. 23172326, 2010.

[50] R. Leyva-Ramos, P. E. Diaz-Flores, J. Leyva-Ramos, and R. A. Femat-Flores, "Kinetic modeling of pentachlorophenol adsorption from aqueous solution on activated carbon fibers," Carbon, vol. 45, no. 11, pp. 2280-2289, 2007.

[51] L. Lv, Y. Zhang, K. Wang, A. K. Ray, and X. S. Zhao, "Modeling of the adsorption breakthrough behaviors of $\mathrm{Pb}^{2+}$ in a fixed bed of ETS-10 adsorbent," Journal of Colloid and Interface Science, vol. 325, no. 1, pp. 57-63, 2008.

[52] X. Yang and B. Al-Duri, "Kinetic modeling of liquid-phase adsorption of reactive dyes on activated carbon," Journal of Colloid and Interface Science, vol. 287, no. 1, pp. 25-34, 2005. 


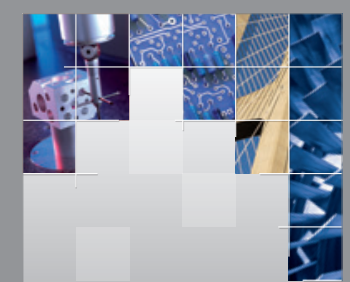

\section{Enfincering}
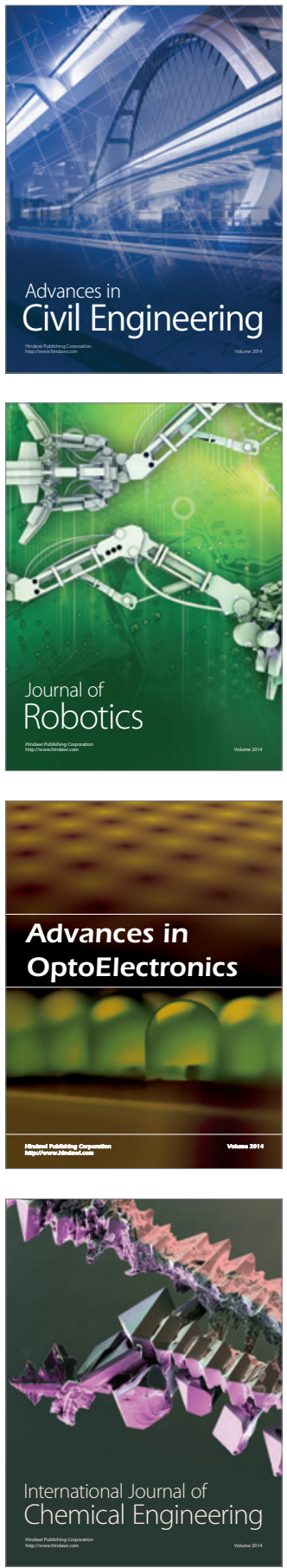

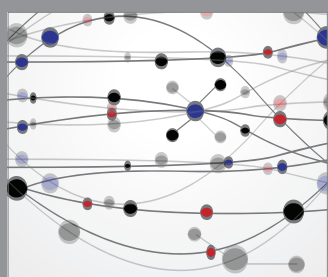

The Scientific World Journal

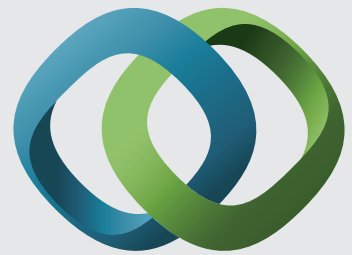

\section{Hindawi}

Submit your manuscripts at

http://www.hindawi.com
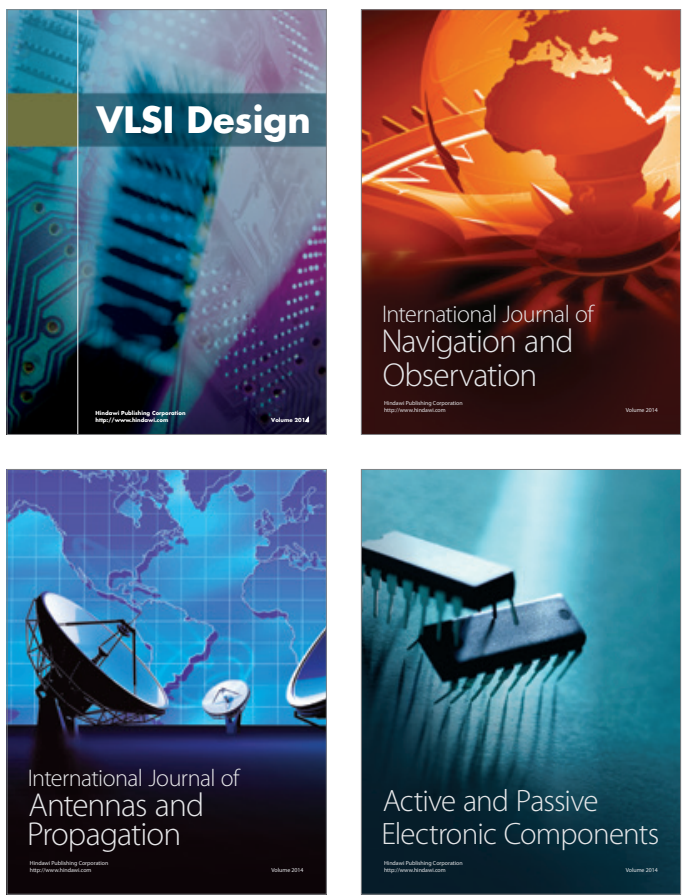
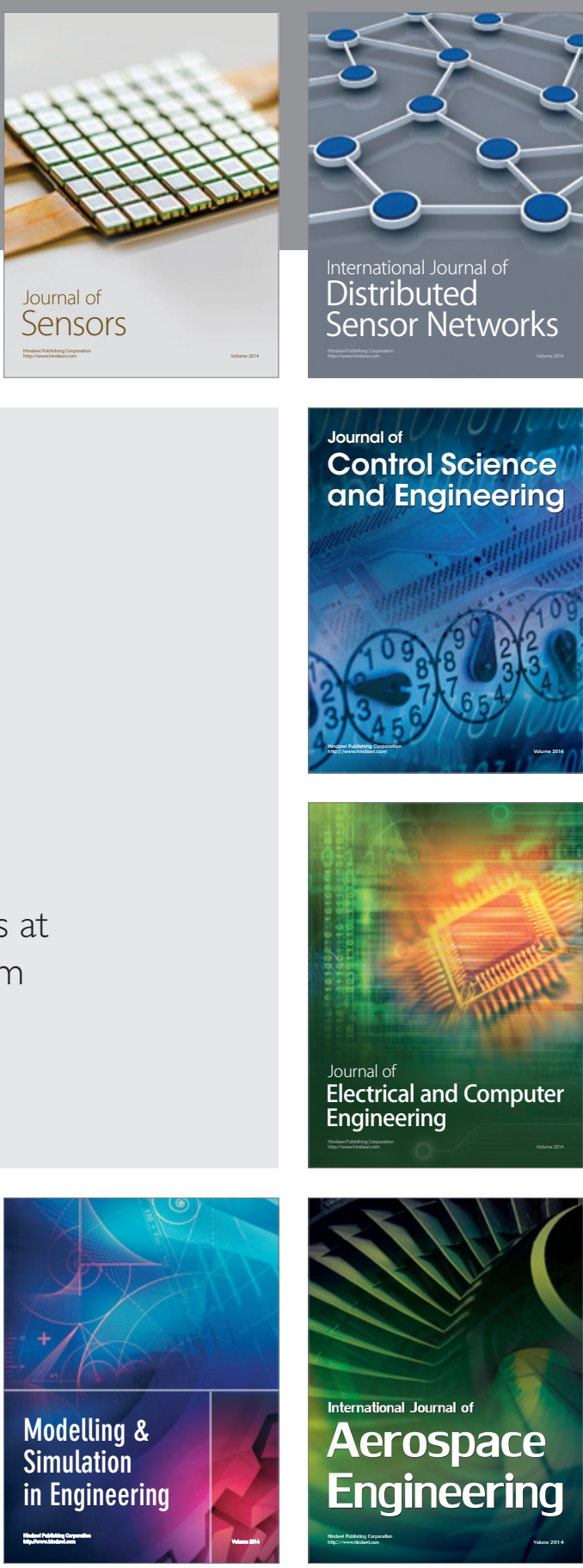

International Journal of

Distributed

Sensor Networks

Journal of

Control Science

and Engineering
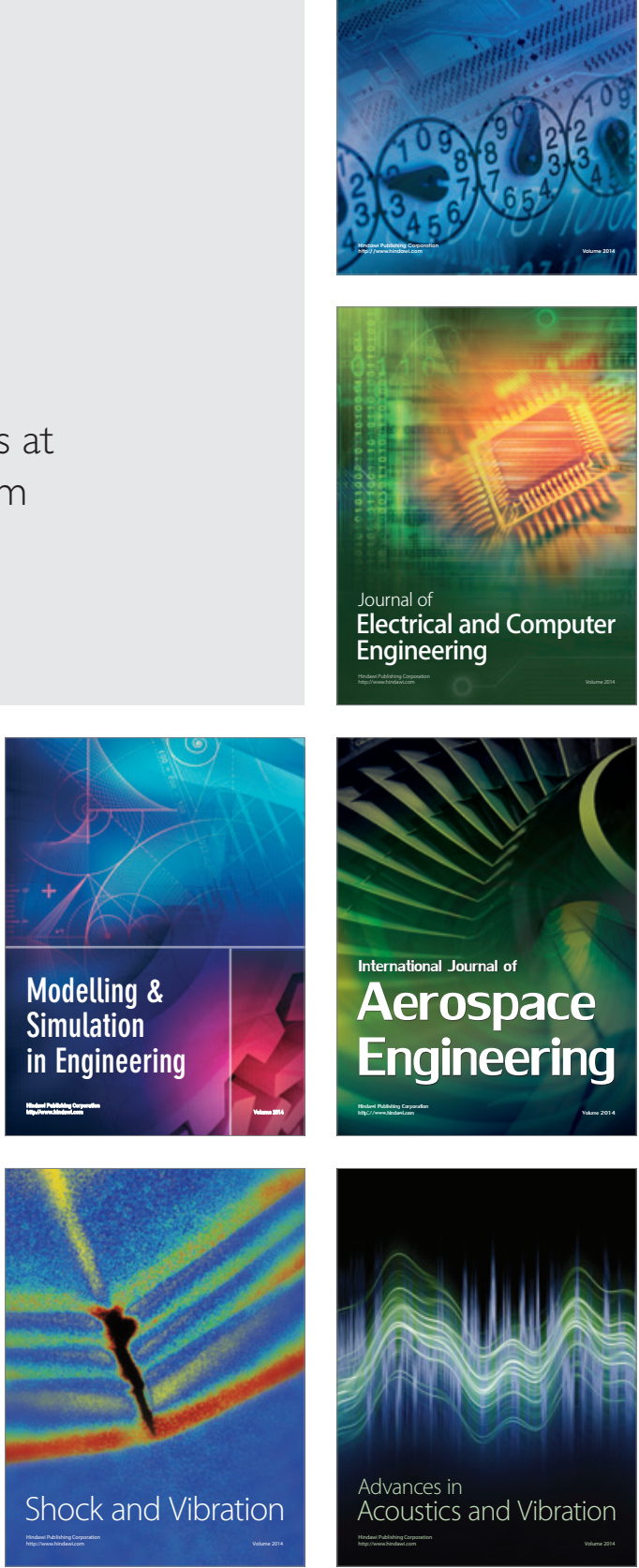